\title{
The effects of major genes on quantitatively varying characters in barley. III. The two row/six row locus $(\mathrm{V}-\mathrm{v})$
}

W. Powell, R. P. Ellis and

W. T. B. Thomas
Scottish Crop Research Institute, Invergowrie, Dundee DD2 5DA, Scotland, U.K.

Inbred lines have been extracted from a barley cross between Dissa (six-row ear type) and Sabarlis (two-row ear type) by single seed descent (SSD) and by the $H$. bulbosum doubled haploid (DH) technique. Estimates of the additive genetic variation from DH and SSD have been compared and demonstrate association between the V-v locus, which conditions ear type, and agronomically important characters. Characters contributing to plant height and biomass production are located near the V-v locus on barley chromosome 2I. The significance of the behaviour of such quantitative trait loci (QTL) and possible applications to plant breeding are discussed.

\section{INTRODUCTION}

The European barley crop is predominantly of the two-row ( $2 r$ ) ear type but some high yielding winter barleys have six-row (6r) ears. High kernel weight is characteristic of the $2 r$ cultivars while the $6 r$ types have a high number of grains per ear. Grain weight is less uniform in the $6 r$ ear because the fertile lateral florets often produce smaller grains than the median florets. The demonstration of difficulty in selecting high yielding segregants from $2 r$ by $6 r$ crosses (Harlan, Martini and Stevens, 1940) was followed by investigations of yield and its components (Wells, 1962; Elliot and Poehlman, 1976; Takahashi, Hayashi and Moriya, 1976; Tandon, Joshi and Jain, 1968). These, together with studies of plant development (Riggs and Kirby, 1978; Kirby and Riggs, 1978), have highlighted the complex nature of character associations in $2 \mathrm{r}$ by 6r crosses.

Ear morphology in $2 \mathrm{r}$ and $6 \mathrm{r}$ barleys, is controlled by two loci, V-v on chromosome 2I (Dewey, 1984) and I-i on chromosome 4I (Sogaard and von Wettstein-Knowles, 1987). The I-i locus is epistatic to V-v so that the genotype VVii has a two-row ear, vvII a six-row ear and VvIi an intermedium type (Nilan, 1964). Thus a range of genotypes can be isolated from a segregating $F_{2}$ population and it can be difficult to discriminate between the parental and recombinant phenotype. Since homozygous $(\mathrm{DH})$ or near homozygous families
(SSD) have been generated the segregants can be more readily classified into the $2 r$ and $6 r$ types.

Various strategies have been developed to examine the effects of the V-v locus on quantitatively varying characters in barley. Wiebe (1952) proposed the use of isogenic lines, to study the nature of quantitative genetic variation. This approach has been adopted by Fasoulas and Allard (1962) and Qualset (1964) to study the effects of small chromosome segments on quantitative traits in barley. The effects of the V-v locus on one or more characters have been demonstrated by Wells (1962), Zali and Allard (1976) and Takahashi et al. (1976). These effects may be due to pleiotropic action of the marker locus or genes governing the quantitative characters located on the same chromosome segment.

Results from long-term studies on composite cross populations of barley, generated by Harlan and Martini (1929) and reviewed by Allard (1988), also provide important information on the effects of single, discrete, loci on quantitative characters. The V-v locus affected most of the quantitative characters studied. The six-row group had 40 per cent more kernels per plant than two-row group and there were significant differences between the groups for all the quantitative characters studied. In addition the V-v locus had large effects on survival and hence adaptation to the environment tested. 
In this study we classified the inbred lines on the basis of alleles at the V-v locus which segregates independently of the I-i locus. The background genetic effect will therefore be nullified (Powell et $a l ., 1985 a, b)$. Furthermore, by comparing the contribution of alleles at this locus to estimates of the additive genetic variance $(D)$ in $\mathrm{F}_{1}$-derived doubled haploid and single seed descent lines, it is possible to assess the relative contribution of pleiotropy and linkage disequilibrium to any character association that may be detected. This information will enable the barley breeder to adopt the most efficient strategy for the deployment of the $\mathrm{V}-\mathrm{v}$ locus in breeding programmes.

\section{MATERIALS AND METHODS}

Sixty-six doubled haploids (DH) were produced from the $F_{1}$ hybrid of a barley (Hordeum vulgare L.) cross, Dissa $(6 r) \times$ Sabarlis $(2 r)$, by the Hordeum bulbosum technique (Kasha and Kao, 1970). Concurrently 49 random $F_{5}$ inbred lines (SSD) were produced by growing a sample of the $F_{2}$ and $\mathrm{F}_{3}$ generations under single seed descent (SSD) (Brim, 1966) followed by the $F_{4}$ generation under normal glasshouse conditions. The parents, DH and $\mathrm{F}_{5} \mathrm{SSD}$ lines were grown in a replicated field experiment in 1986. The experimental design was a randomised complete block with every entry replicated twice. Within blocks each entry was represented by a row of ten seeds, sown at $5 \mathrm{~cm}$ spacings, with a wheat guard at the end of each row. Rows were spaced $20 \mathrm{~cm}$ apart. Each row was harvested as a bundle of a single plants and five randomly chosen plants scored for ear type and the following quantitative characters:

(1) Ear length $(\mathrm{cm})$, measured from the base to the tip of the ear (EL).

(2) Final height $(\mathrm{cm})$, measured from the base of the stem to the collar (HT).

(3) Number of grains on the main-stem (GN).

(4) Weight (g) of grain on the main-stem (MSW).

(5) Weight (g) of the main-stem straw (WS).

(6) Number of fertile tillers per plant (TN).

(7) Thousand grain weight $(\mathrm{g})$, calculated from 3 and 4 above (TGW).

(8) Grain yield (g) from the whole plant (SPY).

(9) Weight of straw (g) from the whole plant (SW).

\section{RESULTS}

The analyses of variance for the DH and SSD populations are given in tables $1(\mathrm{a})$ and $1(\mathrm{~b})$. There are highly significant differences between lines in both populations for all the characters scored. The existence of significant additive genetic variation (D) for all the characters was shown by testing the mean square between lines against the error term. The magnitude of this variation can be assessed from the expected mean squares for the

Table 1

\begin{tabular}{|c|c|c|c|c|c|c|c|c|c|c|}
\hline \multirow[b]{2}{*}{ Item } & \multirow[b]{2}{*}{ d.f. } & \multicolumn{9}{|l|}{ MS } \\
\hline & & EL & HT & GN & MSW & WS & $\mathrm{TN}$ & SW & TGW & SPY \\
\hline \multicolumn{11}{|c|}{ a Analysis of variance for the doubled haploid (DH) families } \\
\hline 1. Between block & 1 & $7 \cdot 9$ & $1040 \cdot 7$ & $8 \cdot 7$ & $6 \cdot 2$ & $1 \cdot 2$ & $37 \cdot 4$ & $150 \cdot 6$ & $39 \cdot 2$ & $114 \cdot 3$ \\
\hline 2. Between lines & 65 & $24 \cdot 6 \ddagger$ & $490 \cdot 8 \ddagger$ & $1733 \cdot 8 \ddagger$ & $1135 \cdot 7 \ddagger$ & $77 \cdot 8 \ddagger$ & $18 \cdot 2 \ddagger$ & $24 \cdot 6 \ddagger$ & $1218 \cdot 1 \ddagger$ & $26 \cdot 1 \ddagger$ \\
\hline $\begin{array}{l}\text { 2r vs. 6r } \\
\text { Lines within }\end{array}$ & 1 & $438 \cdot 9 \ddagger$ & $6753 \cdot 2 \ddagger$ & $63,696 \cdot 1 \ddagger$ & $1743 \cdot 5$ & $654.0 \ddagger$ & $197 \cdot 4 \ddagger$ & $340 \cdot 9 \ddagger$ & $52,781 \cdot 1 \ddagger$ & $78 \cdot 6$ \\
\hline 3. Blocks $\times$ lines & $64(1)$ & 8.7 & $186 \cdot 5$ & 309.9 & $221 \cdot 5$ & $14 \cdot 2$ & $7 \cdot 4$ & $10 \cdot 4$ & 156.9 & $12 \cdot 4$ \\
\hline 4. Within plots & $523(5)$ & $6 \cdot 2$ & 30.9 & $77 \cdot 3$ & $98 \cdot 2$ & $46 \cdot 2$ & $5 \cdot 1$ & $5 \cdot 6$ & $45 \cdot 2$ & $7 \cdot 2$ \\
\hline \multicolumn{11}{|c|}{$b$ Analysis of variance for the single seed descent (SSD) families } \\
\hline 1. Between blocks & 1 & $15 \cdot 2$ & $461 \cdot 3$ & $159 \cdot 2$ & $251 \cdot 1$ & $0 \cdot 1$ & $11 \cdot 9$ & $54 \cdot 8$ & $139 \cdot 7$ & $85 \cdot 8$ \\
\hline 2. Between lines & 48 & $31.9 \ddagger$ & $349 \cdot 2 \ddagger$ & $2022 \cdot 8 \ddagger$ & $1540 \cdot 1 \ddagger$ & $59 \cdot 5 \ddagger$ & $13 \cdot 2 \ddagger$ & $16 \cdot 2 \ddagger$ & $1310 \cdot 9 \ddagger$ & $24 \cdot 7 \ddagger$ \\
\hline 4. Within plots & $370(22)$ & $13 \cdot 1$ & $33 \cdot 3$ & $120 \cdot 0$ & $121 \cdot 6$ & $37 \cdot 6$ & $3 \cdot 2$ & $3 \cdot 5$ & $65 \cdot 2$ & 5.8 \\
\hline
\end{tabular}

$* P<0.05$

$\dagger P<0.01$

$\ddagger P<0.001$. 
Table 2 Estimates of $D$ obtained from the DH and SSD samples together with $\chi^{2}$ values

\begin{tabular}{lrrrrrrrrrr}
\hline & EL & HT & GN & MSW & SW & TN & WS & TGW & SPY \\
\hline DH & $8 \cdot 0$ & $152 \cdot 1$ & $711 \cdot 9$ & $457 \cdot 0$ & $31 \cdot 8$ & $5 \cdot 4$ & $7 \cdot 1$ & $530 \cdot 1$ & $6 \cdot 9$ \\
SSD & $13 \cdot 2$ & $123 \cdot 6$ & $1137 \cdot 9$ & $789 \cdot 7$ & $30 \cdot 2$ & $2 \cdot 4$ & $5 \cdot 5$ & $778 \cdot 7$ & $5 \cdot 7$ & 0.7 \\
$\chi^{2}$ & $1 \cdot 2$ & 0.2 & $2 \cdot 1$ & $2 \cdot 5$ & $0 \cdot 12$ & $1 \cdot 1$ & $0 \cdot 2$ & $1 \cdot 6$ \\
\hline
\end{tabular}

experiment and this is presented for the DH (produced from an $F_{1}$ ) and SSD populations in table 2. Estimates of $D$ obtained from $D H$ and SSD populations will differ in the presence of linkage. A comparison of $D$ from the DH and SSD populations will therefore provide a test for linkage disequilibrium (Powell and Caligari, 1986). The significance of any difference between estimates of $D$ from these two sources can be tested by a standard maximum likelihood model fitting procedure (Pooni et al., 1980). $\chi^{2}$ values for the comparison of the two estimates for each character are also given in table 2 and these are non-significant. However, the detection of significant differences for second order statistics (variances) is far more difficult than for first order statistics (means). For EL, GN, MSW and TGW, estimates of $D$ from the SSD population are at least 40 per cent larger than the corresponding estimate from the $\mathrm{DH}$ population. This suggests an excess of repulsion linkages and is characteristic of the use of relatively diverse parents in a hybridisation programme. For TN, the estimate of $D$ from the DH population is more than double that from the SSD population, suggesting an excess of coupling linkages for this character.

Classification of the recombinant random inbred lines into two groups carrying the alternative allele allows the assessment of the effects of the V-v locus on mean performance in a random genetic background. In the DH population 34 tworow segregants and 22 six-row segregants were identified. An excess of six row (32) segregants over the two row segregants (17) was observed in the SSD population. With the exception of MSW and SPY in the DH population and of HT, MSW, WS, SW and SPY in the SSD population there are highly significant differences between groups (table 1). Means and standard errors for $2 \mathrm{r}$ and $6 \mathrm{r}$ groups are given in table 3 . It is of particular relevance to note that there are significant differences between groups in the DH population for HT, WS and SW but these comparisons are nonsignificant in the SSD populations. Within the DH population the $2 \mathrm{r}$ types tend to be taller, have more tillers, higher thousand grain weight and greater biomass production compared to 6r types. The DH
Table 3 Means and standard errors for the 2 row and 6 row sub-population in the doubled haploid and single descent populations

\begin{tabular}{|c|c|c|c|}
\hline & & 2 row & 6 row \\
\hline EL & $\begin{array}{l}\text { DH } \\
\text { SSD }\end{array}$ & $\begin{array}{l}8 \cdot 16 \pm 0 \cdot 03 \\
7 \cdot 84 \pm 0 \cdot 20\end{array}$ & $\begin{array}{l}6 \cdot 40 \pm 0.12 \\
6 \cdot 27 \pm 0.04\end{array}$ \\
\hline HT & $\begin{array}{l}\mathrm{DH} \\
\mathrm{SSD}\end{array}$ & $\begin{array}{l}82 \cdot 92 \pm 0 \cdot 92 \\
78 \cdot 60 \pm 4 \cdot 25\end{array}$ & $\begin{array}{l}75 \cdot 96 \pm 1 \cdot 64 \\
78 \cdot 60 \pm 1 \cdot 27\end{array}$ \\
\hline GN & $\begin{array}{l}\mathrm{DH} \\
\mathrm{SSD}\end{array}$ & $\begin{array}{l}25 \cdot 18 \pm 0 \cdot 32 \\
23 \cdot 58 \pm 2 \cdot 21\end{array}$ & $\begin{array}{l}46 \cdot 52 \pm 6 \cdot 70 \\
47 \cdot 73 \pm 3 \cdot 95\end{array}$ \\
\hline MSW & $\begin{array}{l}\text { DH } \\
\text { SSD }\end{array}$ & $\begin{array}{l}1 \cdot 27 \pm 0 \cdot 001 \\
1 \cdot 21 \pm 0 \cdot 009\end{array}$ & $\begin{array}{l}1 \cdot 38 \pm 0.007 \\
1 \cdot 44 \pm 0.007\end{array}$ \\
\hline WS & $\begin{array}{l}\text { DH } \\
\text { SSD }\end{array}$ & $\begin{array}{l}1.09 \pm 0.001 \\
0.98 \pm 0.006\end{array}$ & $\begin{array}{l}0.87 \pm 0.003 \\
0.93 \pm 0.002\end{array}$ \\
\hline TN & $\begin{array}{l}\text { DH } \\
\text { SSD }\end{array}$ & $\begin{array}{l}4 \cdot 10 \pm 0 \cdot 05 \\
3 \cdot 94 \pm 0 \cdot 13\end{array}$ & $\begin{array}{l}2.94 \pm 0.05 \\
2.92 \pm 0.03\end{array}$ \\
\hline SW & $\begin{array}{l}\text { DH } \\
\text { SSD }\end{array}$ & $\begin{array}{l}4.56 \pm 0.06 \\
3.92 \pm 0.17\end{array}$ & $\begin{array}{l}3.01 \pm 0.08 \\
3.05 \pm 0.04\end{array}$ \\
\hline TGW & $\begin{array}{l}\text { DH } \\
\text { SSD }\end{array}$ & $\begin{array}{l}50.00 \pm 0.93 \\
50.92 \pm 3.64\end{array}$ & $\begin{array}{l}30 \cdot 59 \pm 0.65 \\
31 \cdot 02 \pm 1.52\end{array}$ \\
\hline SPY & $\begin{array}{l}\mathrm{DH} \\
\text { SSD }\end{array}$ & $\begin{array}{l}4.89 \pm 0.06 \\
4.50 \pm 0.21\end{array}$ & $\begin{array}{l}4 \cdot 15 \pm 0 \cdot 15 \\
4 \cdot 43 \pm 0 \cdot 10\end{array}$ \\
\hline
\end{tabular}

and SSD populations can differ as a consequence of the number of rounds of gametogenesis. Genes controlling the expression of height (HT) and straw weight (WS and SW) may therefore be linked to the $\mathrm{V}-\mathrm{v}$ locus as there were significant differences between groups in the DH population but not in the SSD. For other traits such as EL, GN and TGW the association with the V-v locus persists in the SSD population which indicates close linkage or pleiotropic effects. However, this feature of the data must be considered against the background of differential survival in the SSD population. Although no conscious selection was made, the excess of six row derivatives may reflect a non-random transmission of genotypes during the SSD procedure.

For both the DH and SSD populations the mean squares for the $2 \mathrm{r}$ vs. $6 \mathrm{r}$ item in the analysis of variance were tested against the between lines within groups item. A significant difference between the two groups indicates that a substantial 
Table 4 Estimates of the additive genetics variance $(D)$ and that associated with allelic differences at the V-v locus in the DH and SSD populations

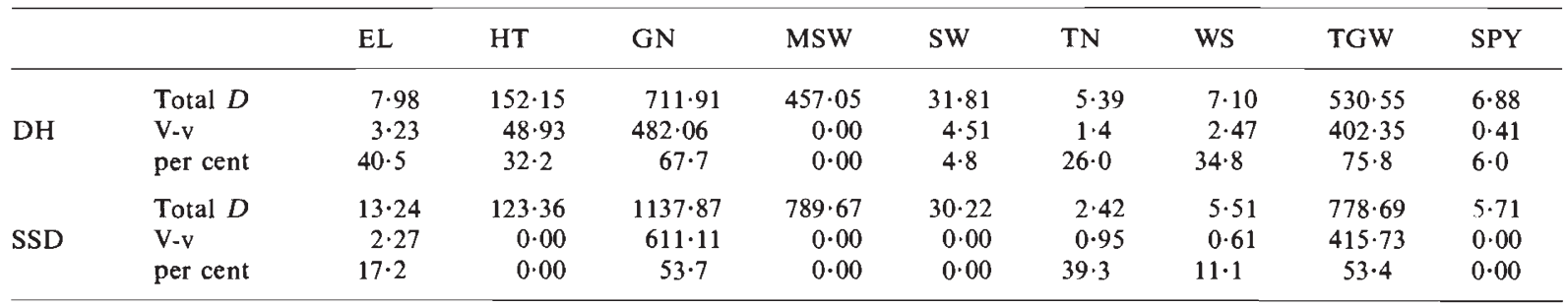

portion of the additive genetic variation $(D v)$ is associated with allelic differences at the V-v locus. The magnitude of this portion is the reduction in the additive genetic variation when it is reestimated from the components of variance for the between lines within groups item (Al-Banna et al., 1984; Powell et al., 1985a, b). Estimates of the total additive genetic variation $(D)$ and that associated with allelic differences at the $\mathrm{V}$-v locus are given in table 4 for the $\mathrm{DH}$ and SSD populations. The contribution of the V-v locus to estimates of the additive genetic variation for characters where there are significant differences between groups in the $\mathrm{DH}$ population ranged from 76 per cent for TGW to 14 per cent for WS. Similarly in the SSD population the highest percentage contribution of the V-v locus to quantitative traits was for GN and TGW (54 and 53 per cent respectively) and the least for EL (17 per cent). With the exception of TN every character measured showed a reduction in the contribution of the $\mathrm{V}-\mathrm{v}$ locus to quantitatively varying characters in the SSD compared to the DH populations. This reduction was most evident for HT, WS and SW. For these characters it is therefore highly probable that the association between them and the V-v locus is due to linkage disequilibrium rather than pleiotropy.

\section{DISCUSSION}

The objective of this investigation was to evaluate the effects of the V-v locus on quantitative agronomic characters. Thoday (1961) emphasised the need to identify genes responsible for the control of metrical characters. The phenotype of a quantitative character is a consequence of both genetic and environmental factors and biometrical procedures have been developed to analyse such traits (Mather and Jinks, 1971). However, biometrical genetics is an extension of Mendelian genetics which stresses the chromosomal location and inheritance of polygenes but need not always reflect control of the classical polygenic type. The chromosomal location of polygenes, or quantitative trait loci (QTLs) of Gelderman (1975), is feasible when genetic markers are available which allow individual chromosomes to be monitored and their effects evaluated following crossing or selfing. Breese and Mather $(1957,1960)$ investigated the distribution of polygene activity affecting chaeta number in Drosphila with mutants and genetic marker stocks. Thoday and colleagues used mutant loci of known chromosomal location to identify and map individual loci affecting quantitative traits in Drosphila (Thoday, 1961; Thompson and Thoday, 1979; Spickett and Thoday, 1966; Thoday et al., 1964). The polyploid nature of wheat has allowed chromosome substitution techniques (Law, 1966) to identify genetic loci affecting time to heading on chromosome 7B of the cultivar Hope. These examples serve to illustrate the fact that genetic loci or adjacent chromosome segments can affect a wide range of quantitatively controlled characters.

Random inbred lines produced by doubled haploidy and single seed descent have been used to examine the effect of the V-v locus on quantitative traits. This strategy has been used previously to examine the effect of the GPert, denso and day length insensitivity loci on agronomically important characters in barley (Powell et al., 1985a,b). Allelic variation at the V-v locus makes a large contribution to the variation for the agronomically important characters EL, HT, GN and TGW. Obviously the V-v locus is associated with a number of characters of agronomic importance. Since the DH and SSD populations differ with respect to the number of rounds of recombination that will have contributed to estimates of $D$, it is possible to assess the relative contribution of pleiotropy and linkage disequilibrium in the control of the characters. If the association is due to linkage disequilibrium a decreasing trend from $\mathrm{DH}$ to SSD in the magnitude of $D_{\mathrm{v}}$ would be evident. This trend is most apparent for EL, HT, SW and WS. 
It must be stressed that the height and straw weight characters are not independent and they exhibited significant differences between allelic classes in the DH but not in the SSD populations. These results strongly suggest that genes controlling height and straw characteristics are linked to the V-v locus on chromosome 2I of barley. Promotor genes having major effects on height have also been located on homoeologous group 2 chromosomes of wheat (Law, 1986).

Small percentage changes were observed in the estimates of $D v$ from the DH and SSD populations for GN and TGW and this would suggest pleiotropic effects of the V-v locus or very tight linkage which has not been broken down following recombination. Takahashi et al. (1976) used a series of isogenic lines to examine the effects of the V-v locus on agronomic characters. The locus was strongly associated with kernel weight and grain number but also weakly associated with stem length (height) and tiller number. Since the isogenic lines would have been generated by several rounds of backcrossing it is likely that genes loosely associated with the V-v locus would have been dispersed by recombination. This study of isogenic lines therefore supports the conclusion that genes controlling height in barley are linked to the V-v locus on chromosome 2I. Start and Riggs (1986) used $F_{4}$ and $F_{5}$ progenies from $2 r$ by $6 r$ crosses to examine the expression of grain number and grain weight in $2 \mathrm{r}$ and $6 \mathrm{r}$ segregants. The $2 \mathrm{r}$ and $6 r$ progenies exhibited a bimodal distribution for grain weight with the $2 r$ segregant having a higher score than the 6r families. Since the progenies will have been exposed to 3-4 rounds of gametogenesis and potential recombination this study provides further support to the conclusion that the V-v locus has pleiotropic effects on grain weight or that the two genetic systems are closely linked. Jensen (1989) has identified a QTL on chromosome 7I of barley that also controls a large portion of the variation in TGW. Selection at this locus combined with the V-v locus may enable improvement in $\mathrm{TGW}$ in the $6 \mathrm{r}$ group.

In a series of experiments on microevolution Allard (1988) described long term studies of allelic frequency changes in composite cross populations of barley. He concluded that certain loci, which included the V-v locus, were under strong selection pressure with an increase in the frequency of the $6 r$ individuals in the populations. Allard concluded "the two-row six-row locus affects developmental processes in ways that leave few quantitative characters untouched". High kernel number per plant, greater spike weight and other characters related to reproductive capacity were associated with predominant alleles i.e., 6r plants in the composite population.

These examples illustrate how selection for alleles at the V-v locus can significantly affect the expression of quantitative traits in barley. Genes controlling height and straw characteristics were shown to be linked to the V-v locus, which is located on chromosome 2I (Nilan, 1964). Following rounds of gametogenesis to produce the SSD population the association between the marker locus and alleles controlling height disappeared. The possibility therefore exists to identify isozyme and molecular markers on chromosome $2 \mathrm{I}$ of barley that may be used to screen indirectly for height and associated traits in segregating populations. This approach has been pursued in maize (Helentjaris and Shattuck-Eidens, 1987) and several quantitative trait loci (QTL) for height have been identified on chromosome 9. The isozyme locus $A C P-1$ and a restriction fragment length polymorphism (RFLP) marker are located near to the centromere of chromosome 9 and are tightly linked to the gibberellic acid dwarf locus, d3. These genetic markers may therefore be used in maize to select for genes controlling height of the maize plant.

For grain number and thousand-grain weight the V-v locus was responsible for a large proportion of the genetic variation in both the DH and SSD populations. In practise it is difficult to distinguish between pleiotropy and tight linkage and for breeding purposes it would appear that the V-v locus behaves as a complex locus assocaited with TGW and GN. Localisation of chiasma formation would result in recombinationally inert regions and it is possible that changes in the positions of crossovers may allow the association between $\mathrm{V}-\mathrm{v}$, TGW and $G N$ to be disrupted and recombinant genotypes to be produced. It is of relevance to note that Gale and Rees (1970) identified a gene or cluster of genes on chromosome 2I of barley that significantly affected chiasma frequency and $2 r$ segregants from a $2 r$ by $6 r$ cross were shown to have a significantly lower mean chiasma frequency. Differences between the $2 \mathrm{r}$ and $6 \mathrm{r}$ groups could also be due to reduced recombination in the $2 r$ group compared to the $6 \mathrm{r}$. Selection is much more efficient when carried out upon inbred lines (Powell and Caligari, 1986) and such a strategy increases the chances of identifying desirable but rare recombinants. This approach would be highly applicable in winter barley breeding programmes where $2 r$ and $6 r$ crosses are often used for the introgression of genes from spring barley. 


\section{REFERENCES}

AL-BANNA, M. K. S., JINKS, J. L. AND POONI, H. S. 1984. The contribution of pleiotropy at the mop loci to continuous variation in Nicotiana rustica. Heredity, 52, 95-102.

ALLARD, R. W. 1988. Genetic changes associated with the evolution of adaptedness in cultivated plants and their wild progenitor. J. Hered., 79, 225-238.

BREESE, E. L. AND MATHER, K. 1957. The organisation of polygenic activity within a chromosome in Drosphila. I. Hair characters. Heredity, 11, 373-395.

BREESE, E. L. AND MATHER, K. 1960. The organisation of polygenic activity within a chromosome in Drosophila. II. Viability. Heredity, 14, 375-399.

BRIM, C. A. 1966. A modified pedigree method of selection in soya beans. Crop Sci. 6, 220.

DEWEY, D. R. 1984. The genomic system of classification as a guide to intergeneric hybridisation within the perennial Triticeae. In: Gustafson, J. P. (ed.) Gene Manipulation in Plant Improvement Plenum, New York, pp. 209-279.

ELLIOTT, W. A. AND POEHLMAN, J. M. 1976. Inheritance of kernel weight in six rowed $\times$ two rowed barley crosses $(H$. vulgare L. $\times$ H. distichum L.). Barley Genetics III. Proc. 3rd Int. Barley Symp., Garching, pp. 678-685.

FASOULAS, A. C. AND ALLARD, R. W. 1982. Non-allelic gene interaction in the inheritance of quantitative characters in barley. Genetics, 47, 899-907.

GALE, M. D. AND REES, H. 1970. Genes controlling chiasma frequency in Hordeum. Heredity, 25, 393-410.

GELDMAN, H. 1975. Investigations on inheritance of quantitative characters in animals by gene markers. I. Methods. Theor. appl. Genet., 46, 319-330.

HARLAN, J. R. 1976. Barley. In Evolution of Crop Plants (ed. N. W. Simmonds), pp. 93-98. Longmans, London.

HARLAN, H. V. AND MARTINI, M. L. 1929. A composite hybrid mixture. J. Am. Soc. Agron., 21, 407-490.

HARLAN, H. V., MARTINI, M. L. AND STEVENS, H. 1940. A study of methods in barley breeding. USDA Tech. Bull. 720.

HELENTJARIS, T. AND SHATTUCK-EIDENS, D. 1987. A strategy for pinpointing and cloning major genes involved in quantitative traits. Maize Genetics Crops Newslett., 61, 88-89.

JENSEN, J. 1989. Estimation of recombination parameters between a quantitative trait locus (QTL) and two marker gene loci. Theor. appl. Genet., 78, 613-618.

KASHA, K. J. AND KAO, K. N. 1970. High frequency haploid production in barley Hordeum vulgare (L.) Nature, 225, 874-876.

KIRBY, E. J. M. AND RIGGS, T. J. 1978. Developmental consequences of two-row and six-row ear type in spring barley. 2. Shoot apex, leaf and tiller-development. J. agric. Sci. (Camb.), 91, 207-216.

LAW, C. N. 1966. The location of genetic factors affecting a quantitative character in wheat. Genetics, 53, 487-498.

LAW, C. N. 1986. The need for a multidisciplinary approach to genetic manipulation in plant breeding. In Genetic Manipulation in Plant Breeding, pp. 867-882. (eds) W. Hon, C. J. Jensen, W. Odenbach and O. Scheider, Walter de Gruyka \& Co., Berlin.
NILAN, R. A. 1964. The Cytology and Genetics of Barley. Monographic supplement No. 3. Research Studies. Washington State University.

MATHER, K. AND JiNKS, J. L. 1971. Biometrical Genetics, 2nd edn. London: Chapman and Hall.

POONI, H. S., JINKS, J. L. AND POONI, G. S. 1980. A general method for the detection and estimation of additive, dominance and epistatic variation for metrical traits. IV. Triple Test Cross analysis for normal families and their selfs. Heredity, 44, 172-192.

POWELL, W., THOMAS, W. T. B., CALIGARI, P. D. S. AND JINKS, J. L. 1985a. The effects of major genes on quantitatively varying characters in barley. 1 . The GPert locus. Heredity, $54,343-348$.

POWELL, W., THOMAS, W. T. B., CALIGARI, P. D. S. AND JINKS J. L. $1985 b$. The effects of major genes on quantitatively varying characters in barley. 2 . The denso and daylength response loci. Heredity, 54, 349-352.

POWELL, W. AND CALIGARI, P. D. S. 1986. Investigations into the linkage of genes controlling individual quantitative characters in barley. Can. J. Genet. Cytol., 28, 63-68.

QUALSET, C. O. 1964. A study of quantitative gene action using isogenic lines of barley. Am. soc. Agron. (Abstr.) pp. 77.

RIGGS, T. J. AND KIRBY, E. J. M. 1978. Developmental consequences of two-row and six-row ear type in spring barley. 1. Genetical analysis and comparison of mature plant characters. J. agric. Sci. (Camb.), 91, 199-205.

SOGAARD, B. AND VON WETTSTEIN-KNOWLES, P. 1987. Barley: genes and chromosomes. Carlsberg Res. Commun., 52, 123-196.

SPICKETT, S. G. AND THODAY, J. M. 1966. Regular response to selection. 3. Interaction between located polygenes. Genet. Res. 7, 96-121.

START, N. D. AND RIGGS, T. J. 1986. Mean grain-weight in the progeny of two-rowed $\times$ six-rowed crosses in spring barley. Genet. Agr., 40, 65-72.

TAKAHASHI, R., HAYASHI, J. AND MORIYA, I. 1976. Basic studies on breeding barley by the use of two-rowed and six-rowed varietal crosses. Barley Genetics III. Proc. 3rd Int. Barley Genetics Symposium, Garching, pp. 662-677.

TANDON, J. P., JOSHI, A. B. AND JAIN, K. B. L. 1968. Genetic analysis of yield in a six row and two row varietal cross in barley. I. Genetics of yield and its primary components. Ind. J. Genet. Pl. Breed., 28, 239-251.

THODAY, J. M. 1961. Location of polygenes. Nature, 191, 368370.

THODAY, J. M., GIBSON, J. B. AND SPICKETT, S. G. 1964. Regular response to selection. Genet. Res., 5, 1-19.

THOMPSON, J. M. AND THODAY, J. M. 1979. Quantitative Genetic Variation. Academic Press.

WELLS, S. A. 1962. Effect of the V locus on yield of adapted barley varieties. Can. J. Pl. Sci., 42, 169-173.

Wiebe, G. A. 1952. Isogenic analysis in barley. Am. Soc. Agron. (Abstr.).

ZALI, A. A. AND ALLARD, R. W. 1976. The effect of the level of heterozygosity on the performance of hybrids between isogenic lines of barley. Genetics, 84, 765-775. 